Blow-off mechanisms of turbulent premixed bluff-body stabilised flames operated with vapourised kerosene fuels

R. S. Pathania*, A. W. Skiba, R. Ciardiello, E. Mastorakos

Department of Engineering, University of Cambridge

Trumpington Street, Cambridge CB2 1PZ, UK

Tel: +44 1223332641

Email: rsp37@cam.ac.uk

Colloquium 5: Turbulent Flames

Total length of paper (including title block and abstract): 8.0 pages (Method 2, Latex count)

We do not agree to pay colour reproduction charges (Figures 1-7). 


\title{
Blow-off mechanisms of turbulent premixed bluff-body stabilised flames operated with vapourised kerosene fuels
}

\author{
R. S. Pathania*, A. W. Skiba, R. Ciardiello, E. Mastorakos \\ Department of Engineering, University of Cambridge, Cambridge CB2 1PZ, UK
}

\begin{abstract}
The lean blow-off (LBO) behaviour of unconfined lean premixed bluff-body stabilised flames with various fuels was investigated. Methane and vapourised ethanol, heptane, Jet-A1, and an alternative alcohol-derived kerosene (Gevo) were used. $\mathrm{OH}^{*}$ chemiluminescence $(5 \mathrm{kHz}), \mathrm{OH}$ - and Fuel-PLIF $(5 \mathrm{kHz})$, and $\mathrm{CH}_{2} \mathrm{O}-\mathrm{PLIF}(10 \mathrm{~Hz})$ were deployed. For all fuels, as the flame approached LBO fragmentation was observed downstream, the two sides of the flame merged at the axis, pockets of $\mathrm{OH}$ and $\mathrm{CH}_{2} \mathrm{O}$ were found in the recirculation zone (RZ), and eventually the individual fragments extinguished. The $\mathrm{CH}_{2} \mathrm{O}$ seemed to enter into the $\mathrm{RZ}$ from downstream early in the LBO process, with reactants following suit at times closer to LBO. During LBO, the integrated $\mathrm{OH}^{*}$ signal decreased slowly to zero and the duration of this transition was $\sim 25\left(d / U_{B O}\right)$ in the methane and ethanol flames and $\sim 60\left(d / U_{B O}\right)$ in flames operated with heptane and the two kerosenes (where $d$ is the bluff-body diameter and $U_{B O}$ the LBO velocity). This large difference could be due to re-ignitions of partially-quenched fluid inside the RZ during the LBO event. Additionally, for the same bulk velocity, the kerosene flames blow-off at higher equivalence ratios than the single-component fuelled flames, which is possibly due to the higher Lewis number and lower extinction strain rates of these fuels. The results suggest that the blow-off mechanism is qualitatively similar for each of the fuels; however, the complex chemistry associated with heavy hydrocarbons appears to result in a prolonged LBO event.
\end{abstract}

Keywords: Premixed turbulent flames, Vapourised kerosenes, Lean blow-off duration

${ }^{*}$ Corresponding author:

Email address: rsp37@cam. ac.uk (R. S. Pathania) 


\section{Introduction}

Turbulent lean premixed flames are of considerable importance as they facilitate efficient combustion and low NOx production [1]. One common way to stabilise these flames is by creating a wake or recirculation zone (RZ) behind a bluff body. The process by which the flame anchors behind the bluff body involves the continuous interaction of hot products in the RZ with the combustible mixture in the shear layer. Several experiments were performed to understand the flame behaviour at stable and near blow-off conditions [2-7]. Based on these experiments, various theories have been proposed, attributing blow-off to conditions wherein the chemical time scales exceeded those associated with the turbulent flow field [2]. In addition, it was found that the flame changes shape as it approaches lean blow-off (LBO). Namely, Kariuki et al. [6] found that methane flames change from cylindrical to "M-shaped" as they approach LBO. Results from Refs. [3, 4] of propane flames suggested that as blow-off is approached, the degree of interaction between the shear layer and the flame-front increases. They also observed that localised regions of high strain rate caused flame-front extinction within the shear layer, forming a hole that facilitated the entrainment of fresh reactants into the RZ. In contrast, Dawson et al. [5] and Kariuki et al. [6], who investigated methane flames, did not notice significant extinction in the shear layer; rather they observed it to occur in the downstream region of the RZ, which leads to the eventual advection of cold reactants into the RZ.

Via joint planar laser-induced fluorescence (PLIF) imaging of $\mathrm{OH}$ and $\mathrm{CH}_{2} \mathrm{O}$, Kariuki et al. [8] imaged heat release (HR) layers in their methane flames as LBO was approached. Breaks in the HR regions, which were interpreted as local extinction events, were observed along with the shear layers of their flames. However, no apparent connection between the cold reactants in the RZ and the annular reactant jet was observed, suggesting that reactants did not enter the RZ from the sides. There findings were consistent with OH-PLIF images presented in Refs. [5, 6], which suggested the presence of reactions within the RZ during the LBO transient. Significant accumulation of $\mathrm{CH}_{2} \mathrm{O}$ was found inside the $\mathrm{RZ}$ close to LBO [8]. The difference in the flame behaviour at LBO between Refs. [3, 4] and Refs. [5, 6] could be attributed to the different burner geometries [9] and the Lewis number $(L e)$. Namely, the propane flame in Refs. [3, 4] has $L e>1$, rendering it more susceptible to local extinction due to strain than a methane flame with $L e \approx 1$. Yet, for methane, extinction events appear to primarily result from flame-flame touching and hence incomplete combustion.

Each of the above-mentioned studies considered the structure of gaseous flames. In contrast, recent studies with heavy hydrocarbon flames which have high $L e$, demonstrated that such flames are more prone to extinction than simpler fuels $[10,11]$. The DNS study of Aspden et al. [12] reported that flame-front wrinkling is suppressed due to high $L e$, which leads to reduced turbulent flame speeds. Such results suggest that the LBO process of heavy hydrocarbon fuels may be different from that associated with simpler gaseous fuels. Since heavy hydrocarbon liquid fuels are more commonly used in practice, there is a need to study turbulent, premixed, heavy hydrocarbon flames near LBO. In this work, the structure and transient aspects of turbulent, lean, unconfined bluff-body stabilised premixed flames (non-swirling) of vapourised liquid fuels were investigated during LBO. Three single-component fuels (methane, used as reference; and vapourised ethanol and n-heptane), and two different multi-component kerosene fuels were studied. The kerosene fuels consisted of a conventional Jet-A blend (A2), and an alternative Gevo alcohol-tojet (ATJ) kerosene (C1), following the notation used in the USA National Jet Fuel Combustion Programme [13]. The chemical composition and other key features of these kerosene fuels are provided in Ref. [13]. The two kerosenes studied have significantly different derived cetane numbers (DCN): 48.8 and 17.1 for $\mathrm{A} 2$ and $\mathrm{C} 1$, respectively [13]. It has been suggested that lowtemperature chemistry characteristics of a fuel may correlate to its LBO condition [10], which further motivates the comparison between the fuels performed here.

The objective of this paper is to provide a detailed comparison between the behaviour of various fuels during LBO in terms of structure and duration by imaging with laser-based diagnostics. The results help identify the extent to which previous findings with simple fuels can be extrapolated to more complex ones.

\section{Experimental setup and methods}

Figure 1 shows a schematic of the bluff-body burner employed here. It is similar to that employed in Refs. [5, $6,8]$, the only difference being its smaller bluff-body diameter $(d=23 \mathrm{~mm})$, providing a blockage ratio of $43 \%$. The bluff body was mounted at the centre of a $35 \mathrm{~mm}-$ tube via a 6.5-mm diameter rod. A vapouriser system, a scaled-up version from Ref. [10], was used to vaporise the liquid fuels. The inlet air was heated using inline heaters and then passed through the mixing chambers where the fuel was injected through nebulizers (Meinhard, TR-30-A10). The mixing chambers were wrapped 
with heating tape and all pipes with insulation. Preliminary Mie scattering and Phase Doppler Anemometry experiments suggested that $99.9 \%$ of the fuel exiting the burner was vaporised. The temperature of the air/fuel mixture was measured with K-type thermocouples at the exits of the vapouriser and the burner. The temperature at the exit of the burner was maintained at $393 \pm 5$ K. Figure 1 (right) splits the flame into different regions to facilitate later discussions: the "anchoring" region is defined by $x<15 \mathrm{~mm}$, while the "downstream" region corresponds to $x>15 \mathrm{~mm}$, where $x$ is axial distance from the bluff body. Both areas include the RZ as well as the shear layers and the annular jet.



Figure 1: Schematic of burner showing critical dimensions and different regions of the flame.

The flame structure and the LBO transient were visualised with $5 \mathrm{kHz} \mathrm{OH} *$ chemiluminescence. The $\mathrm{OH}^{*}$ imaging system consists of a CMOS high-speed camera equipped with a two-stage high-speed intensifier gated at $130 \mu \mathrm{s}$. A UV $100 \mathrm{~mm} \mathrm{f} / 2.8$ lens fitted with a bandpass filter (270-370 $\mathrm{mm})$ was attached to the IRO.

PLIF imaging of $\mathrm{OH}$ was performed to visualise the 2-D structure of flames as they approaches LBO. OH excitation was achieved via the high-speed $(5 \mathrm{kHz})$ output from a dye laser (Sirha Credo) pumped by the 532nm output of a solid-state Nd:YAG laser (JDSU Q201HD) with 18-ns pulse durations. The tunable dye laser produced a beam near $566 \mathrm{~nm}$, which was frequencydoubled to yield a beam near 283-nm with an average power of $300 \mathrm{~mW}(60 \mu \mathrm{J} /$ pulse $)$. Specifically, this beam was tuned to excited the $\mathrm{Q}_{1}(6)$ line in the $A^{1} \Sigma-X^{2} \Pi$ $\left(v^{\prime}=1, v^{\prime \prime}=0\right)$ band of $\mathrm{OH}$. A laser sheet 32 (tall) $\times 0.2$ (thick) $\mathrm{mm}^{2}$ was obtained using sheet forming optics (i.e. plano concave lens $(30 \mathrm{~mm})$ and 2 cylindrical convex lenses $(100 \mathrm{~mm}))$. Note that wavelength $(\lambda)$ calibration was performed at the start of each day by maximizing the signal from a stable flame and shifts in $\lambda$ were not apparent during the measurements as the signal-to-noise ratio $(\mathrm{SNR})$ remained constant $(\approx 6: 1)$. Here, SNRs were computed as in [14] by dividing the average signal within a region by the standard deviation of the signal within that region. The same laser setup was used to obtain Fuel-PLIF images from the
A2 flames. The only difference from the OH-PLIF was that the laser beam was detuned from the $\mathrm{Q}_{1}(6)$ line to avoid the excitation of the $\mathrm{OH}$ radical. For both $\mathrm{OH}-$ and Fuel-PLIF, the same high-speed camera as for the $\mathrm{OH}^{*}$ imaging was used. However, the IRO was gated at $300 \mathrm{~ns}$ and for OH-PLIF the lens was fitted with a narrow bandpass filter of $310 \pm 10 \mathrm{~nm}$ (Edmund, 34980). Since fuel fluoresces over a broad spectral range $(\sim 300$ - $420 \mathrm{~nm}$ ) [15], a long pass filter of $320 \mathrm{~nm}$ was instead employed for the fuel-PLIF measurements.

PLIF of $\mathrm{CH}_{2} \mathrm{O}$ was used to visualise the preheat zone or partially-burnt reactants in the $\mathrm{CH}_{4}$ and A2 flames. The frequency-tripled output (near $355 \mathrm{~nm}$ ) from a $10 \mathrm{~Hz} \mathrm{Nd:YAG} \mathrm{laser} \mathrm{(Continuum} \mathrm{Surelite),} \mathrm{with}$ $\sim 100 \mathrm{~mJ} /$ pulse, was used to excite multiple transitions within the $4_{0}^{1}$ band of the $A^{2} A_{1} \longleftarrow X_{1} A^{1} 4_{0}^{1}$ system of $\mathrm{CH}_{2} \mathrm{O}$. A 38-mm cylindrical concave lens and a 500$\mathrm{mm}$ spherical bi-convex lens were used to produce a well-expanded sheet with dimensions 52 (tall) $\times 0.25$ (thick) $\mathrm{mm}^{2}$. Fluorescence resulting from the incident laser light was collected by an intensified CCD camera (LaVision, Nanostar) gated to $100 \mathrm{~ns}$ and equipped with a Zeiss $100 \mathrm{~mm}$ f/2 lens, which was fitted with a multiband filter (FF01-CH2O-50).

The average signal originating from the camera offset, laser background, and flame chemiluminescence emissions were subtracted from the OH-PLIF, FuelPLIF, and $\mathrm{CH}_{2} \mathrm{O}$-PLIF images. Following this subtraction, the instantaneous OH- and Fuel-PLIF images were divided by the laser sheet Gaussian profile measured using a cell filled with an optically thick solution of Rhodamine $6 \mathrm{G}$, and then the images were median filtered with a kernel size of $5 \times 5$ pixel ${ }^{2}$ to increase the $\mathrm{SNR}$ to $\approx 6: 1$. The laser sheet used for $\mathrm{CH}_{2} \mathrm{O}$ imaging was larger and the vertical variation in the energy was negligible. Therefore, no laser sheet corrections were performed. For A2, a low intensity contribution to the $\mathrm{CH}_{2} \mathrm{O}$ signal due to fuel fluorescence in the reactants far from the flame-front was visible. This was $\approx 2 \%$ of the maximum value of the signal by comparison to the methane flame.

Blow-off was achieved by keeping the bulk air velocity $U_{b}$ constant at $23.5 \pm 1.5 \mathrm{~m} / \mathrm{s}$ and slowly reducing the fuel at a rate of $0.02 \mathrm{~g} / \mathrm{s}$ every 20 seconds until the flame was no longer visible.

\section{Results and Discussion}

This section presents results on the duration of blowoff events collected with all fuels. Additionally, the flame structure during the blow-off transient with A2 fuel was investigated with $\mathrm{OH}-\mathrm{PLIF}, \mathrm{CH}_{2} \mathrm{O}-\mathrm{PLIF}$, and 
Fuel-PLIF. These imaging results are to be contrasted against those obtained from methane and ethylene flames in previous works [5-8], highlighting differences between the structure of flames near LBO as more complex hydrocarbons are considred.

\subsection{Blow-off duration}

Figure 2a shows a temporal sequence of $\mathrm{OH}^{*}$ chemiluminescence images with the A2-fuelled flame during a LBO event. During its approach to LBO, the flame became progressively shorter and survived for tens of milliseconds within the RZ. Additionally, the $\mathrm{OH}^{*}$ chemiluminescence signal was confined to the RZ during the LBO event. Such images were used to evaluate the duration of the LBO event for all fuels. Namely, the $\mathrm{OH}^{*}$ signal was integrated over the imaged area and plotted $v s$. time. The onset of the blow-off event was associated with a decrease in the $\mathrm{OH}^{*}$ signal, which appears to be linked to flame shortening and fragmentation, as shown in Fig. 2a. The same procedure was followed by Dawson et al. [5] with methane flames, where the blowoff duration was found to be on the order of $15 d / U_{B O}$, where $U_{B O}$ was the bulk velocity at blow-off.
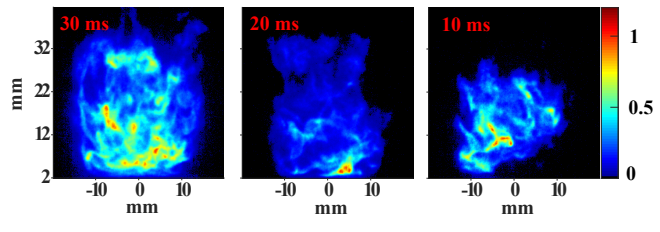

(a) $\mathrm{OH}^{*}$ chemiluminescence images during $\mathrm{LBO}$ for $\mathrm{A} 2$.

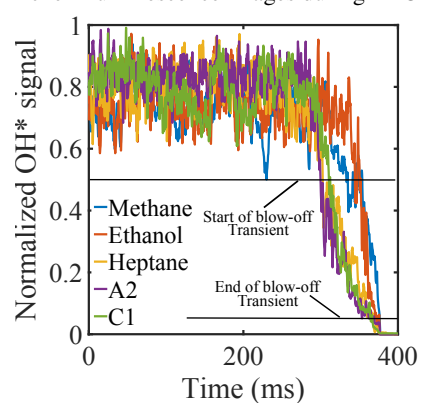

(b) Area-integrated $\mathrm{OH}^{*} v s$. time for all fuels

Figure 2: (a) $\mathrm{OH}^{*}$ chemiluminescence Images of the LBO transient with $\mathrm{A} 2$ and (b) integrated $\mathrm{OH}^{*}$ for methane, ethanol, heptane, A2 and $\mathrm{C} 1$. In (b), the data presented is the average of five LBO events.

Figure $2 b$ shows the average of five spatially integrated $\mathrm{OH}^{*}$ signals during blow-off. The extinction duration, $\tau_{\text {ext }}$, was quantified as the time it took the $\mathrm{OH}^{*}$ signal to decay from $50 \%$ to $5 \%$ of the time-averaged level before LBO (the $\mathrm{OH}^{*}$ signal never grows back if the signal drops lower than $50 \%$ ). The results are presented in Table 1. Since the blow-off event was not directly controlled, the original $\mathrm{OH}^{*}$ time series were shifted to coincide with the disappearance of $\mathrm{OH}^{*}$ signal. The value of $\tau_{\text {ext }}$ depends on the threshold value used. However, choosing different thresholds did not affect the trends between $\tau_{\text {ext }}$ and fuel type. In the current study, $\tau_{\text {ext }}$ was $\approx 22$ and 24 for methane and ethanol, respectively. Whereas, for heptane, $\mathrm{A} 2$ and $\mathrm{C} 1$ it was $64.60 \mathrm{~ms}, 63.20 \mathrm{~ms}$, and $54.60 \mathrm{~ms}$, respectively (around $\left.60 d / U_{B O}\right)$.

This suggests that blow-off is more sudden in the methane and ethanol flames as compared to those operated with heavier hydrocarbons. It may be possible that during the LBO transient the RZ contains fluid (discussed later through the PLIF images) spanning the whole range of possible values of the progress variable (i.e. fresh reactants, partially-burnt reactants, and fullyburnt products). Thus, some low-temperature chemistry, that would be more pronounced in the large hydrocarbons compared to $\mathrm{CH}_{4}$ and $\mathrm{C}_{2} \mathrm{H}_{5} \mathrm{OH}$, may be present, which leads to a continuous re-ignition of flame fragments in the $\mathrm{RZ}$ hence prolonging the complete LBO event [16].

Table 1: Values of $\tau_{\text {ext }}$ evaluated for different fuels for $U_{b}=23.5 \pm 1.5$ $\mathrm{m} / \mathrm{s}$.

\begin{tabular}{lccccc}
\hline Fuel & $\mathrm{U}_{B O}(m / s)$ & $\phi$ & Le & $\tau_{\text {ext }}(\mathrm{ms})$ & $\tau_{\text {ext }} /\left(\mathrm{d} / \mathrm{U}_{b o}\right)$ \\
\hline Methane & 24.8 & 0.615 & 0.98 & 22.70 & 23.50 \\
Ethanol & 24.5 & 0.63 & 1.68 & 24.40 & 26.00 \\
Heptane & 22.8 & 0.635 & 2.8 & 64.60 & 64.03 \\
A2 & 23.8 & 0.68 & 4.6 & 63.20 & 65.40 \\
C1 & 23.8 & 0.71 & 5.0 & 54.60 & 56.50 \\
\hline
\end{tabular}

\subsection{Species distributions during $L B O$}

In this Section, the qualitative distributions of $\mathrm{OH}$, Fuel, and $\mathrm{CH}_{2} \mathrm{O}$ at various instants during $\mathrm{LBO}$ are described. Only images from A2 flames are considered as such flames permit fuel-PLIF imaging and prior studies of methane flames have presented PLIF images of $\mathrm{OH}$ and $\mathrm{CH}_{2} \mathrm{O}$ [8] in this burner. Also, A2 is interesting as it is the most chemically complex fuel considered here. In interpreting the results, it might be convenient to consider that Fuel-PLIF represents low values of the progress variable; $\mathrm{CH}_{2} \mathrm{O}$ comes from intermediate values, and $\mathrm{OH}$ comes from fluid particles with high progress variable values [17]. 


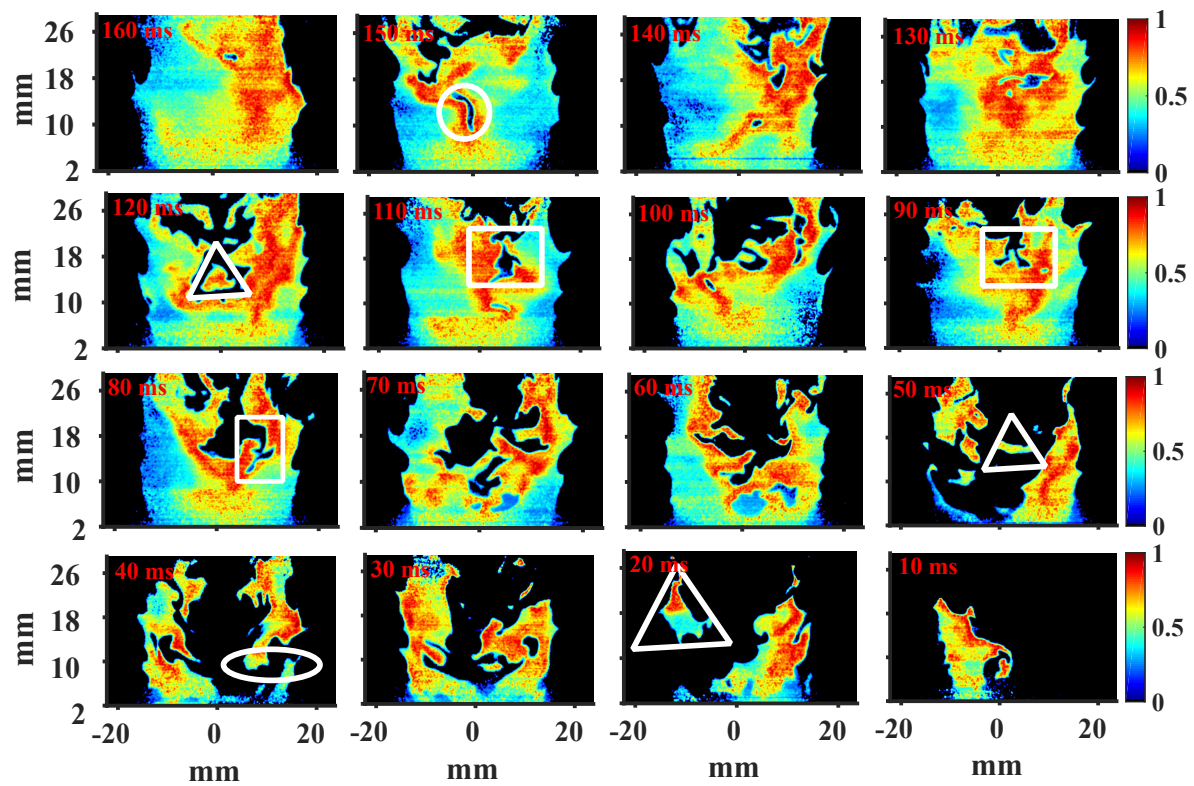

Figure 3: OH-PLIF sequence during a blow-off event for A2-fuelled flame at $U_{b}=23.5 \mathrm{~m} / \mathrm{s}$.

Figure 3 presents instantaneous OH-PLIF images before the blow-off event of an A2 flame and the corresponding video is provided in Supplementary Material. A substantial change in the flame structure was observed as LBO was approached with an overall decrease in $\mathrm{OH}$ signal. The $\mathrm{OH}$ regions become distorted inside the RZ, and pockets filled with and void of $\mathrm{OH}$ were observed simultaneously. The flame becomes shorter with the peak OH-PLIF signal lying within the RZ above the bluff-body.

Specifically, as LBO was approached, four dominant events were observed: (i) appearance of finger-like structures (marked with rectangles); (ii) formation of regions void of $\mathrm{OH}$ (marked with circles); (iii) breaks along the flame-front near the shear layer (marked with white ellipse); and (iv) formation of pockets of $\mathrm{OH}$ PLIF signal in the RZ (marked with triangles). The finger-like structures were noticed to enter into the RZ from its downstream end. Similar findings on the formation of finger-like structures (long ligaments void of $\mathrm{OH}$ ) were reported in experimental studies with propane, ethylene and methane $[6,7]$. In our experiments, these structures were observed to enter from downstream and penetrate deep into the RZ and reach close to the bluff-body, as shown in the OH-PLIF video in the Supplementary Material. These voids burned out as they moved towards the bluff-body. In addition, it was found that sometimes the regions void of OH-PLIF travel towards the flame-front at the shear layer causing what appears to be local extinction, which leads to further regions void of $\mathrm{OH}$ that are eventually convected into the RZ. The absence of $\mathrm{OH}$ in a specific region (e.g. lowest and left-most panel of Fig. 3) can only correspond to either extinction or the presence of reactants (fresh or with intermediate species like $\mathrm{CH}_{2} \mathrm{O}$ ). Inclusion of $\mathrm{CH}_{2} \mathrm{O}$ - and Fuel-PLIF imaging facilitates to distinguish between these two options.

Figure 4 shows sequences of $\mathrm{CH}_{2} \mathrm{O}$-PLIF images from methane and A2 flames during a blow-off event. Since the $\mathrm{CH}_{2} \mathrm{O}$-PLIF images were taken at $10 \mathrm{~Hz}$, the error in determining the blow-off instant is $\sim 100 \mathrm{~ms}$. However, comparison between the fuels is still instructive. It can be seen that $\mathrm{CH}_{2} \mathrm{O}$ enters the $\mathrm{RZ}$ from the downstream region. Both fuels exhibit thin layer-like preheat zones in the anchoring region and in the shear layer up to a distance of $\sim 1 d$ from the bluff body. Further downstream, the $\mathrm{CH}_{2} \mathrm{O}$ layers begin to broaden. In the methane flames such broadening is limited to 2-3 $\mathrm{mm}$ and the $\mathrm{CH}_{2} \mathrm{O}$ occupies layer-like regions. In contrast, $\mathrm{CH}_{2} \mathrm{O}$ layers in the $\mathrm{A} 2$ flame become so broad (i.e. $\sim 1 d$ thick) in the downstream region that they no longer exhibit layer-like features.

The individual pockets of $\mathrm{CH}_{2} \mathrm{O}$-LIF signal inside the RZ confirms that the voids present in the OH-PLIF images (marked with circles on the OH-PLIF images, Fig. 3) likely consist of $\mathrm{CH}_{2} \mathrm{O}$. Furthermore, it can be seen from Fig. 4 that the $\mathrm{CH}_{2} \mathrm{O}$ encapsulates the $\mathrm{RZ}$ through the merging of layers from opposite sides of the 
burner in the downstream region (size of the RZ can be around 1.5 to 2 the bluff-body diameter [6]), confirming that blow-off is associated with the merging of the flame branches from either side of the bluff body in this burner. Moreover, oxidation of heavy hydrocarbon fuels start at low/intermediate temperature $(600$ - $900 \mathrm{~K})$ [18]. Thus, the presence of broad regions of $\mathrm{CH}_{2} \mathrm{O}$ inside the RZ in A2 flame implies the dominance of lowtemperature oxidation reactions.
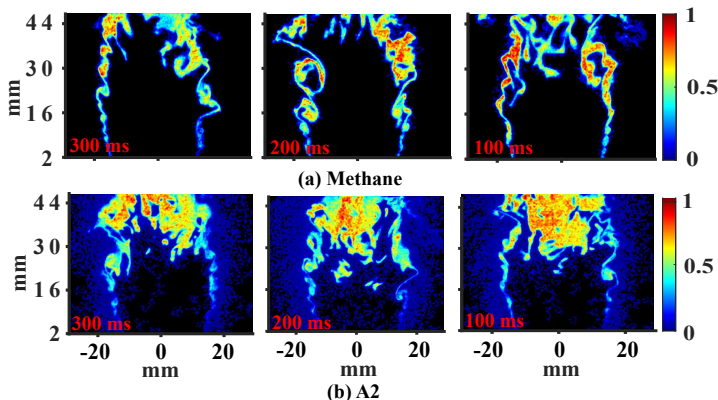

Figure 4: $\mathrm{CH}_{2} \mathrm{O}$-PLIF sequences during a blow-off event for methane and A2-fuelled flames at $U_{b}=23.5 \mathrm{~m} / \mathrm{s}$. The images were taken at an frequency of $10 \mathrm{~Hz}$.

Figure 5 shows Fuel-PLIF images from an A2 flame (a corresponding video is included in the Supplementary Material). Prior to LBO, the fuel is confined to the annular jet, where it appears continuous and uniform. The absence of breaking and of reduction in intensity in the Fuel-PLIF signal there suggests there is little entrainment of ambient air. Approximately $50 \mathrm{~ms}$ before LBO, pockets of Fuel-LIF signal were observed in the RZ and even near the bluff-body (see Fig. 5). Entry of fuel into the RZ can be correlated to the breaking in the flame-front, as shown in OH-PLIF image at $50 \mathrm{~ms}$ (Fig. 3). Finally, at LBO, the RZ is completely filled with fresh reactants.

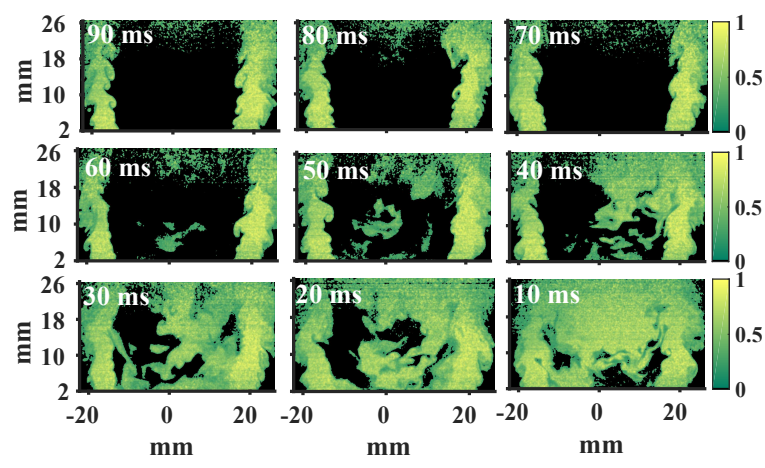

Figure 5: Sequence of Fuel-PLIF images during a blow-off event for the A2-fuelled flame, bulk velocity $=23.5 \mathrm{~m} / \mathrm{s}$.
The OH-PLIF images were further analysed to estimate the number of $\mathrm{OH}$-pockets that form during LBO. Figure 3 shows the RZ filled with $\mathrm{OH}$, but as the flame approaches blow-off the initially continuous $\mathrm{OH}$ region in the RZ shreds into many small pockets. Figure $6 \mathrm{a}$ shows the average (based on 10 blow-off events) number of OH-LIF pockets from the A2 and methane flames as they approached blow-off. To identify individual pockets, the OH-PLIF images were binarized based on their $10 \%$ contour. Then the total number of individual islands of $\mathrm{OH}$ were counted in each instantaneous image. It can be observed that in both flames there was a sudden rise in the number of $\mathrm{OH}$ pockets roughly 20 ms before complete extinction, consistent with the insights obtained from the time sequence in Fig. 3 that the $\mathrm{OH}$-containing region disintegrates before LBO.

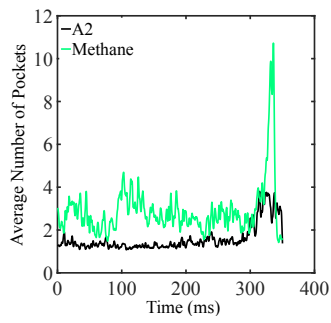

(a) Average number of pockets of $\mathrm{OH}$-LIF signal.

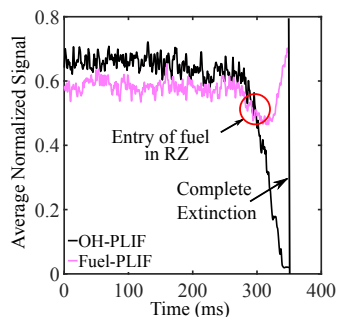

nal.
Figure 6: Plot showing the time average of 10 blow-off events. (a) Variation of number of OH-LIF signal pockets as the blow-off was approached for methane and A2. (b) Variation of OH- and Fuel-PLIF signal with A2 as the blow-off was approached.

Figure $6 \mathrm{~b}$ shows the area-integrated OH-PLIF and Fuel-PLIF (averaged over 10 LBO movies) from the A2 flame. Juxtaposition of these two time series shows, on average, the relative instant at which fuel enters the RZ compared to the time the $\mathrm{OH}$ disappears. After a short transient, the Fuel-PLIF signal started increasing as the $\mathrm{OH}-\mathrm{PLIF}$ signal kept decreasing. Based on these averages, the critical time at which the fuel begins entering the RZ was $\sim 45 \mathrm{~ms}$ before complete extinction.

Further analysis was performed on the OH-PLIF images to quantify the fragmentation of the flames $\left(F_{c}\right)$. The quantification was performed on binarised $\mathrm{OH}$ PLIF images. Namely, the area and equivalent diameter of each pocket in these images were determined and subsequently grouped according to the latter. This approach was applied to two separate portions of each image sequence (i.e. 50 - $25 \mathrm{~ms}$ before LBO and 25 ms to LBO) to determine how $F_{c}$ varied as LBO was approached. The logarithmic distribution of objects of a particular diameter is profiled in Fig. 7. It was ob- 


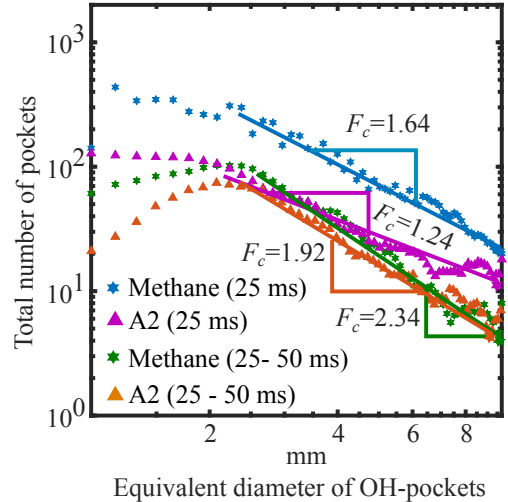

Figure 7: Number of $\mathrm{OH}$ pockets $v s$. their equivalent diameter averaged over 10 blow-off events. The degree of fragmentation $\left(F_{c}\right)$ is represented by the slope of the curves. Two set of images were analysed, 50 - $25 \mathrm{~ms}$ before LBO and $25 \mathrm{~ms}$ to LBO.

served that the methane flame exhibits higher $F_{c}$ than A2. These findings are consistent with the results presented in Fig. 6a as the methane flame showed more number of pockets. Moreover, $F_{c}$ decreases as LBO is approached, which may be due to the disappearance of small OH-PLIF pockets as the flame approaches LBO (see Fig. 3).

\subsection{Discussion}

From the preceding presentation of $\mathrm{OH}^{*}, \mathrm{OH}-\mathrm{PLIF}$, $\mathrm{CH}_{2} \mathrm{O}$-PLIF, and Fuel-PLIF images, the blow-off mechanism can be divided into four steps: (i) fragmentation of the flame in the downstream region; (ii) entry of $\mathrm{CH}_{2} \mathrm{O}$ into the $\mathrm{RZ}$, forming the first pockets void of OH-PLIF signal; (iii) breaking of the flame-front in the shear layer; (iv) fuel entry into the $\mathrm{RZ}$ as shown in Fig. 5, which mixes with the $\mathrm{CH}_{2} \mathrm{O}$ and offers the second reason for the absence of $\mathrm{OH}$.

Considering the first step, the change in flame shape and closing of the flame in the downstream region of the $\mathrm{RZ}$ as LBO was approached is consistent with previous studies $[3,5,6,8]$. The blow-off event begins with the shredding of flame in the downstream region. The fragmentation of the $\mathrm{OH}$ structures in this region may be due to localised extinction. PIV measurements made in a methane flame (i.e. Ref. [6]) showed that the turbulent Karlovitz number increases with distance along the flame brush, and hence the opportunity for extinction is expected to increase with axial distance. The results are consistent with the time-averaged $\mathrm{OH}^{*}$ chemiluminescence images (Fig. 2a), which show the presence of reactions in the RZ above the bluff-body and shortening of the flame as it approaches blow-off. They are also similar to those in Refs. [6-8], which were acquired from methane and ethylene flames. Simultaneous measurement of $\mathrm{OH}$ and PIV in Ref. [3] suggested that these localised extinctions are due to locally high strain rates induced along the flame when they exceed the corresponding extinction strain rate. However, this explanation is probably insufficient for $\mathrm{CH}_{4}$ flames in the presence of back-support from adiabatic hot products [6, 8]. Hence, it seems more likely that a $\mathrm{CH}_{4}$ flame would extinguish locally due to flame-flame merging and loss of this back-support. Indeed, results in Ref. [19] indicate that local extinctions of highly turbulent methane flames are primarily promoted by reduction in back support.

Considering Step (ii), as described in Refs. [3, 6], as LBO was approached the flames begin to experience a higher degree of incomplete combustion, which allows partially-burnt reactants (e.g. $\mathrm{CH}_{2} \mathrm{O}$ as shown in Fig 4) to enter the RZ. Ultimately, the smaller volume of fullyburnt hot products inside the RZ weakens the back support of the flame at the shear layer and leads to Step (iii), i.e. to an increased level of localised extinction events, and to the penetration of cold reactants into the RZ (Step (iv); Fig. 5) until the flame is globally extinguished.

Note from Table 1 that the LBO of the kerosene flames occurs at a higher equivalence ratio compared to the other fuels. Kerosene has a $L e \approx 4.6$, in contrast to the smaller hydrocarbons that have lower Le. Strained counterflow laminar premixed flame calculations (not shown here) suggest that in the back-to-back configuration, kerosene flames extinguish at a lower strain rate compared to the other fuels, consistent with the present stability trend.

The blow-off behaviour observed here has some similarities, but also some differences to the one proposed by Refs. [3, 4] for a propane flame. It was suggested that local extinction occurs in the shear layer due to high strain rate, which leads to the entry of cold reactants into the RZ. In contrast, the current study with A2 and previous studies with $\mathrm{CH}_{4}$ [6-8] showed that the LBO mainly begins in the downstream region of the $\mathrm{RZ}$ where local extinction is driven by flame-flame merging (see Fig. 3 at $120,110,90,70 \mathrm{~ms}$ ) or localised flame extinction in the shear layer due to high stretch; this leads to the substantial flow of partially-burnt and unburnt reactants into the RZ from the downstream stagnation point, further destabilising the flame close to the bluff body. The discrepancies in the behaviour of blow-off in Refs. [3, 4] to those of the current study may be due to the burner configuration [20], which can alter the level of strain "felt" by the flame in the shear layer; this is a function not only of the incoming turbulence and shear rate, but also of the angle the flame makes with the flow.

A clear difference between the A2- and methane- 
flames is that the former exhibit a higher degree of $\mathrm{CH}_{2} \mathrm{O}$-layer broadening. Such broad layers in the former are likely to interact with $\mathrm{OH}$ and fresh reactants within the RZ of such flames (see Figs. 3, 4 and 5). This combination is likely to promote the influence of low-temperature chemistry in A2 flames, which likely contributes to their longer blow-off duration. In other words, the combination of low-temperature reactions with intermittent product pockets likely increases the longevity of these more complex-fueled flames.

\section{Conclusions}

The flame structure and LBO duration of unconfined premixed, vapourised flames stabilised on a bluff-body burner, during blow-off were investigated using $\mathrm{OH}^{*}$ chemiluminescence, $\mathrm{OH}-, \mathrm{CH}_{2} \mathrm{O}$ - and Fuel-PLIF imaging. From these images, it was found that the flame typically extinguished first in the downstream region (i.e. near the stagnation point above the bluff body). From there, $\mathrm{CH}_{2} \mathrm{O}$ penetrates the $\mathrm{RZ}$ from there, which destabilise the shear layer flame enabling a relatively long process where the flame is progressively eliminated and the RZ fills with $\mathrm{CH}_{2} \mathrm{O}$ and fresh reactants. $\mathrm{CH}_{2} \mathrm{O}$ regions were found to be much larger in kerosene (A2) as opposed to methane flames. Also, the duration of a LBO event was 2.5 times longer in the former than in the latter. This was also true for heptane and an alternative kerosene $(\mathrm{C} 1)$. This long duration and the presence of large regions of $\mathrm{CH}_{2} \mathrm{O}$ inside the $\mathrm{RZ}$ of more complex-fueled flames suggests the possibility of significant low-temperature reactions occurring in the RZ during LBO. This indicates that LBO knowledge based on $\mathrm{CH}_{4}$ cannot be fully transposed to heavier hydrocarbon fuels that are ubiquitous in practice.

\section{Acknowledgments}

The authors would like to thank Drs. Tim Edwards and Med Colket for assistance with the standardised kerosene fuels used in this study. The authors are grateful to Prof. Egolfopoulos for sharing his vapouriser designs and to Drs. Jenni Sidey, Patton Allison and Pedro de Oliveira for their experimental support. Rohit S. Pathania is grateful for the financial support of Cambridge Trust and SERB India.

\section{References}

[1] A. W. Lefebvre, D. R. Ballal, Gas turbine combustionAlternative fuels and emissions, CRC press, Taylor and Francis group, NY, 2010.
[2] J. P. Longwell, E. E. Frost, M. A. Weiss, Flame stability in bluff body recirculation zones, Ind. Eng. Chem. 45 (8) (1953) 16291633.

[3] S. Chaudhuri, S. Kostka, M. W. Renfro, B. M. Cetegen, Blowoff dynamics of bluff body stabilized turbulent premixed flames, Combust. Flame 157 (4) (2010) 790 - 802.

[4] S. Chaudhuri, B. M. Cetegen, Blowoff characteristics of bluffbody stabilized conical premixed flames with upstream spatial mixture gradients and velocity oscillations, Combust. Flame 153 (4) (2008) $616-633$.

[5] J. R. Dawson, R. L. Gordon, J. Kariuki, E. Mastorakos, A. R. Masri, M. Juddoo, Visualization of blow-off events in bluffbody stabilized turbulent premixed flames, Proc. Combust. Inst. 33 (1) (2011) 1559-1566.

[6] J. Kariuki, J. R. Dawson, E. Mastorakos, Measurements in turbulent premixed bluff body flames close to blow-off, Combust. Flame 159 (8) (2012) 2589-2607.

[7] J. Kariuki, A. Dowlut, R. Balachandran, E. Mastorakos, Heat release imaging in turbulent premixed ethylene-air flames near blow-off, Flow, Turbul. Combust. 96 (4) (2016) 1039-1051.

[8] J. Kariuki, A. Dowlut, R. Yuan, R. Balachandran, E. Mastorakos, Heat release imaging in turbulent premixed methane-air flames close to blow-off, Proc. Combust. Inst. 35 (2) (2015) $1443-1450$.

[9] J. F. Driscoll, Turbulent premixed combustion: Flamelet structure and its effect on turbulent burning velocities, Prog. Energy Combust. Sci. 34 (1) (2008) 91 - 134

[10] F. Carbone, J. L. Smolke, A. M. Fincham, F. N. Egolfopoulos, Comparative behavior of piloted turbulent premixed jet flames of c1c8 hydrocarbons, Combust. Flame 180 (2017) 88 - 101.

[11] A. Aspden, A numerical study of diffusive effects in turbulent lean premixed hydrogen flames, Proc. Combust. Inst. 36 (2) (2017) 1997 - 2004.

[12] A. Aspden, J. Bell, M. Day, F. Egolfopoulos, Turbulence-flame interactions in lean premixed dodecane flames, Proc. Combust. Inst. 36 (2) (2017) 2005 - 2016.

[13] M. Colket, J. Heyne, M. Rumizen, M. Gupta, T. Edwards, W. M. Roquemore, G. Andac, R. Boehm, J. Lovett, R. Williams, J. Condevaux, D. Turner, N. Rizk, J. Tishkoff, C. Li, J. Moder, D. Friend, V. Sankaran, Overview of the national jet fuels combustion program, AIAA J. 55 (4) (2017) 1087 - 1104

[14] M. J. Papageorge, T. A. McManus, F. Fuest, J. A. Sutton, Recent advances in high-speed planar Rayleigh scattering in turbulent jets and flames: increased record lengths, acquisition rates, and image quality, Applied Physics B 115 (2) (2014) 197-213.

[15] M. Orain, P. Baranger, C. Ledier, J. Apeloig, F. Grisch, Fluorescence spectroscopy of kerosene vapour at high temperatures and pressures: potential for gas turbines measurements, Appl. Phys. B 116 (3) (2014) 729-745.

[16] N. Rock, B. Emerson, J. Seitzman, T. Lieuwen, Near-lean blowoff dynamics in a liquid fueled combustor, Combust. Flame 212 (2020) $53-66$.

[17] Y.-C. Chen, R. W. Bilger, Experimental investigation of threedimensional flame-front structure in premixed turbulent combustion-i: hydrocarbon/air bunsen flames, Combust. Flame 131 (4) (2002) $400-435$.

[18] W. Liang, R. Mével, C. K. Law, Role of low-temperature chemistry in detonation of n-heptane/oxygen/diluent mixtures, Combust. Flame 193 (2018) 463 - 470.

[19] E. Mastorakos, A. Taylor, J. Whitelaw, Extinction of turbulent counterflow flames with reactants diluted by hot products, Combust. Flame 102 (1) (1995) $101-114$.

[20] S. J. Shanbhogue, S. Husain, T. Lieuwen, Lean blowoff of bluff body stabilized flames: Scaling and dynamics, Prog. Energy Combust. Sci. 35 (1) (2009) 98-120. 